\title{
Psychological Wellbeing of Elders as a Function of Religious Involvement, Spirituality and Personal Meaning in Life
}

\author{
Belay Tefera Kibret* and Gerum Tareke
}

Department of Psychology, School of Psychology, College of Education and Behavioral Studies, Addis Ababa, Ethiopia

\begin{abstract}
A developmentally salient concern so characteristic of the growing persons in the latter years is psychological well-being. This study attempted to examine the status of this psychological well-being of elders aged 60-89 years and possible existential (religious involvement, spirituality and personal meaning in life) and demographic factors (gender, age and education) affecting this status. Data were collected from 329 elders (162 males and 167 females) in Dessie Town through rating scales. Findings indicated that most elders had moderate and above moderate score on self-esteem and autonomy. Moreover, reasonable number of elders had moderate and high score on depression. There existed a significant difference between males and females in personal meaning in life, autonomy, selfesteem, and depression; males better in psychological well-being. In addition, one-way ANOVA results showed significant differences in autonomy, self-esteem, and depression scores due to differences in educational level. Stepwise regression analysis finally yielded that personal meaning in life, spirituality, and religious involvement together contributed significantly to the variance in autonomy, self-esteem and depression. Personal meaning in life had the highest contribution to the total variance in autonomy, self-esteem and depression. The contribution of spirituality was significant to the variance in autonomy, depression and self- esteem of the elderly. Furthermore, religious involvement was found to make significant contribution to the variance in self-esteem and depression but not autonomy.
\end{abstract}

Keywords: Psychological well-being; Existential factors; Autonomy; Self-esteem; Depression; Personal meaning; Spirituality; Religious involvement; Elderly

\section{Introduction}

Psychological wellbeing is a subjective human functioning that has increasingly taken an important space in psychological literature and mental health. It has been differently defined as 'living life in a fully and deeply satisfying manner' [1-3], 'an overall satisfaction and happiness' [4], 'thoughts and feelings about life and how events in the environment are perceived' [5], 'subjective report of one's own life' [6], 'a mental state of being healthy, satisfied' [4], 'an absence of illness' [7], and 'selfacceptance, autonomy, environmental mastery, purpose in life, positive relations with others, and personal growth' [8].

After reviewing the empirical literature in the field, Andresen et al. [9], Rosenberg [10] and Ryff [7], have found that the vast majority of surveys of psychological well-being have utilized one or more of three types of criteria that in a way has also served as three important components of psychological wellness: mood (depressed, anxious), global self-esteem, self-concept and positive psychological functioning (mainly autonomy). Autonomy is considerably related in the literature to such qualities as self-determination, independence, and the regulation of behavior from within [8]. Self-esteem viewed as a component of mental health, as well as a component of general assessment of life as well as psychological well-being. Self-esteem is also defined in various ways as feelings of self-worth and self-respect [10], level of self-valuation [11]. Depression, on the other hand, is a state of psychological ill-being including such excessive negative feelings as anxiety, worry, sorrow, tiredness, hopelessness, sleeplessness and loneliness being amidst people [9].

The later years in human life cycle are usually characterized by important psychological and physical changes which may reshape a person's way of living [12]. With increasing age, the relative importance of psychological wellbeing will change so that elders will have significantly different relationships among the components of psychological well- being more than the younger participants [8]. For example, depressive symptoms are among the most commonly reported complaints of older adults aged 60 or older [13]. It has long been understood that many of the negative experiences associated with depression are also associated with aging in general [14].

Despite the difficulty in defining psychological well-being, researchers have been curious about the antecedent conditions that contribute to psychological well-being for many years and have identified numerous variables that appear to be associated with the construct. Some have suggested that psychological wellness stems from healthy diet while others have postulated that psychological wellness is a function of youth. Other previous studies have postulated that psychological well-being is a result of socio-demographic characteristics, particularly income, physical health status [15]. However, researchers have found in more recent years that existential factors (spirituality, religious involvement, and personal meaning in life) are most salient explaining psychological wellbeing than previously postulated (i.e., socio-demographic) factors (income, social support, physical health) as in, for example, experiences in previous research suggesting the fact that relative to early-onset depression late-life depression is pretty much influenced by existential factors compared to any other factors [16]. It is now postulated that the presence or absence of internally generated personal and existential resources such as accessibility to both formal and informal religious activities, spiritual experiences including

*Corresponding author: Kibret BT, Department of Psychology, School of Psychology, College of Education and Behavioral Studies, Addis Ababa, Ethiopia Tel: +251111 225949; E-mail: belaytefera@yahoo.com

Received: June 19, 2017; Accepted: June 23, 2017; Published: June 30, 2017

Citation: Kibret BT, Tareke G (2017) Psychological Wellbeing of Elders as a Function of Religious Involvement, Spirituality and Personal Meaning in Life. Clin Exp Psychol 3: 153. doi: 10.4172/2471-2701.1000153

Copyright: @ 2017 Kibret BT, et al. This is an open-access article distributed under the terms of the Creative Commons Attribution License, which permits unrestricted use, distribution, and reproduction in any medium, provided the original author and source are credited. 
frequency of private prayer and devotion, feelings of closeness to a power greater than oneself [17], and a well-developed personal meaning in life [18] may be potent predictors of psychological wellbeing in late life. Some scholars $[19,20]$ have shown that religion and spirituality are presumed not only to endow older adults' lives with meaning and purpose but to give them hope and the courage to cope with stressful situations and circumstances. Frequently, however, this hope, optimism and personal meaning for life and forms of spiritual coping could not be well developed and need to be stimulated and reinforced by caregivers and health providers $[20,21]$.

Despite the recent social gerentological movement in studying religion and spirituality in building resilience over the challenges of aging, very little of an empirical nature is known about the contribution of religion, spirituality and personal meaning in life to the psychological wellbeing of older adults. Furthermore, several researchers have not devoted as much research and attention to the problems of older persons as they have to those of younger's [12]. The neglect of the problems of aging should obviously be over and aging must be a legitimate subject of the study so that it would at the same time inspire public discourse and eventually bring concerns of the elderly in the mainstream public policy and community programming. More interestingly, in Ethiopia aging as a course and as an issue has become newer and research on problems of older persons was mainly limited to determining prevalence rates and examining the socio- demographic correlates of such psychological experiences as self-esteem, loneliness, depression, perceived social support and psychosocial profile of elders [22-26]. None of these previous studies in Ethiopia had attempted to examine the possible contributions of religious involvement, spirituality and personal meaning in life for building the psychological wellbeing of the elders. However, experience shows that these existential factors even seem to assume an interestingly special place in the life of many elderly in Ethiopia.

The present research is intended to bring this less investigated and yet important issue to the attention of researchers by way of taking the first step to reflect on three interrelated basic question: What is the status of psychological wellbeing of the elders? Is there a significant statistical difference in psychological well-being as a result of sex, education, and age and what is the contribution of existential factors in predicting psychological well-being of the elderly?

\section{Methods}

This study examines the psychological wellbeing (autonomy, self-esteem, depression) of the elderly in Dessie Town and the effect of some selected demographic factors (age, sex, and education level) and existential factors (religious involvement, spirituality and personal meaning in life). The psychological wellbeing measures are criterion variables and the existential factors (religious involvement, spirituality and personal meaning in life) and demographic factors (age, sex, educational levels) are predictor variables. In order to achieve the stated objectives, a quantitative approach of data collection has been used.

\section{Participants}

Based mainly on convenience and cost, the study is conducted on those elders, aged 60 years and above, who live in Dessie Town. The Town is located in South Wello of the Amhara Regional State, about 404 kilometers North East of Addis Ababa. The economic activity of the Town is highly dependent on trade and agriculture. All the major religious groups (Muslims, Orthodox Christians, and Protestants) are available in the Town.
The town has ten Kebeles with a total population of about 8,497 (4,080 males and 4,417 females) elders living in this Town [27]. The procedure of sampling was such that initially, 10 kebeles were stratified by location: Northern (kebele 7and 9), Southern (kebele 1 and 2), Central (kebele 8 and 10), Eastern (kebele 3and 5); and Western (kebele 4 and 6) Dessie. From each of these five strata, a random sample of one kebele was taken using a lottery method. Accordingly the sampled kebeles were 2, 4, 5,8, and 9. Then, each Kebele office was visited to secure information about the elderly. Documents were secured in each case having complete information about house numbers, names of household members with their age, and status in the family (wife, husband, and child). Once this information was secured, persons with ages 60 years and above (i.e., 3,289 of whom 1,618 were males and 1,671 were females) were listed out in all the five kebeles. From this total list of elders, 329 ( 162 males and 167 females) were randomly drawn from each kebele using the proportionate stratified sampling technique. This sample size is almost $10 \%$ of the population as it was suggested by some researchers [28] that a sample size of about $10-20 \%$ would suffice in a survey design with a population size as big as our present case.

\section{Tools}

Data were collected using rating scales already developed to measure both psychological wellbeing and existential factors. Psychological Wellness is an individual's evaluation of their own overall psychological health consisting of such specific attitudes as autonomy, self-esteem, and depression.

Autonomy: It is defined as the extent to which elderly have firm stand to act in their way and rely on judgments of selves to make important decisions rather than influenced by the social pressures. Ryff [7] autonomy scale was used to assess this sense of self- determination, independence, and freedom from norms. The instrument includes 9 items scored on a six point Likert-type scale (strongly disagree $=$ 1 , disagree $=2$, slightly disagree $=3$, slightly agree $=4$, agree $=5$, strongly agree $=6$ ); negatively phrased items being reversed in valence. The sub scale has very good indices of internal consistency (Table 1). Several studies Ryff [8] have also testified the construct and criterion validity of this scale reporting that autonomy has direct relationship with spirituality and meaning in life and negative relationships between depression and physical health. The autonomy scale is a 9 item scale each with minimum score 9 and maximum score 54 . Based on the scales of scoring, the cuts off points used to classify the elders 'status of autonomy under each category were also given in Table 1 .

Self-esteem: It refers to an elderly person's general judgment (evaluation) of the worth or value of the self as a whole like. The Rosenberg Self-Esteem Scale [10] used to measure participants' global self-esteem. The scale is the most widely used self-esteem measure in social science research [29]. Each of the ten statements measured overall feelings of self-worth or self-acceptance. A 4-point Likert-type scale was prepared to measure respondents' level of agreement with each item (where ' 0 ' represented strongly Disagree.... and ' 3 ' represented Strongly Agree); negatively phrased items again scored reversing the valence in the opposite direction. The cuts off points used to classify the elders' status of self-esteem are given in Table 1.

Depression: Andresen et al. developed a 10-item four point (' 0 ' or rarely/ none of the time to ' 3 ' or all of the time) Likert-type depression scale to measure depressive moods in the general population characterized by one or more of a number of symptoms including being bothered by unusual things or excessive worry, feelings of sadness or misery, the feeling that even the smallest tasks are almost impossible, 
feelings like failures, worthlessness loneliness, and sleep problems. Andresen et al. reported that the scale has shown good internal consistency (Cronbach alpha $=0.97$ ), predictive accuracy, convergent and discriminate validity, correlated positively with poor health status, and low income and negatively correlated to meaning in life. The depression scale is a 10-item scale each with minimum score 0 and maximum score 30 . Based on the scales of scoring, the cuts off points were also indicated in Table 1.

Existential factors are composed of three major components that are all measured through scales already developed in previous research: religious involvement scale [30], Spiritual Perspective Scale [31], and The Personal Meaning Index [32].

Religious involvement scale: Religious involvement is a set of behaviors that reflect public or formal participation in religious activities and practices such as importance of religion, frequency of church or mosque, and group worship attendance, comfort from religion, and accessibility to religious support services. Religious Involvement scale used was developed by Chatters et al. [30] to measure involvement in religious activities. The 6 items of the scale elicit a subject's perceptions of religious views and their involvement in religious-related activities. A 6-point Likert-type scale was used and scored by calculating the mean across all items. Item responses are averaged into a single score that ranges from 1 to 6 , with higher scores indicating a higher level of religious involvement. Alpha coefficients of the previous study was 0.76 were found for the community elderly samples. Religious involvement was scored on a six point Likert format (Strongly disagree $=1$ to Strongly agree $=6)$ [30].

Spiritual perspective scale: It encompassing private prayer read or heard spiritual related materials, need of spiritual guidance, importance of spirituality and devotional subjective activity in an attempt to establish a relationship with some higher power greater than oneself. This was developed by Reed [31] was used to measure the saliency of spiritual perspective and practices in a person's life. The 10 items of the SPS elicit a subject's perceptions of spiritual views and spiritual-related activities. A 6-point Likert-type scale was used and scored by calculating the mean across all items. None of the items refers to a specific religion or church. Item responses are averaged into a single score that ranges from 1 to 6, with higher scores indicating a higher level of spirituality. Reliability of the SPS was estimated by Cronbach's alpha at 0.90 with healthy, hospitalized and seriously ill adults [31]. Although the SPS yields a single score and does not contain subscales. The SPS has been widely used in numerous studies with elders, caregivers and patients with various chronic illnesses and healthy elders has maintained reliability of 0.92 to 0.94 [33]. Spirituality scale was scored on a six point scale Likert format, whereby, Strongly disagree $=1$, Disagree $=2$, Slightly Disagree $=3$, Slightly Agree $=4$, Agree $=5$, and Strongly agree $=6$ points [31].

The personal meaning index: personal meaning in life: Refers to having life goals, a sense of direction from the past, in the present, and toward the future and having a sense of order and reason for existence and a clear sense of personal identity. One of the measures of personal meaning in life that appears to be more resistant to non-invariance is the Personal Meaning Index, a 16-item measure of the existential belief that life is meaningful [32]. The Personal Meaning Index is a composite of the Purpose and Coherence subscales dimensions of the 48 -item of the multidimensional Life Attitude Profile-Revised (LAP-R: [32]). Although originally developed for use with elders, the Personal Meaning Index has been applied to all ages ranging from adolescence to older adulthood [21,34]. Scores can range from 16 to
80. A high score reflects a strong sense of having achieved life goals, having a mission in life, having a sense of direction, having a sense of order and reason for existence, and having a logically integrated and consistent understanding of self, others, and life in general. The internal consistency for the Personal Meaning Index was 0.91 [33]. Personal Meaning Index was scored on a seven (5) point scale Likert format, where by strongly disagree $=1$, Disagree $=2$, undecided $=3$, Agree $=4$ and Strongly agree $=5$ points [33]

\section{Procedures}

The procedures of validating the scales proceeded in some steps. First, the researchers conducted a face validity check on the scales and decided that these selected scales would serve the purpose. The second step was an extension of this face validity check that attempted validating this view by subjecting the scales to expert judgment of four professionals having long years of relevant research and teaching experiences. These experts commented on the validity of all scales (format, content coverage, and relevance) and these comments were incorporated for further refinement. Once the validity check is established, then forward and backward Amharic translation was made from and to English using two linguists who are familiar to both languages, one doing the forward and the other the backward translations. Some discrepancies in the two versions were then readjusted. Finally, pilot-test was conducted to solve ambiguity (clarity, language structure problems), to check validity, reliability and feasibility of the instrument. In the present study, the Amharic versions of the instruments were administered to systematically selected 30 (12 male and 18 female) elders from Kebele 8 of Dessie Town. These subjects were excluded from the final analysis. Internal consistency reliability of the Amharic versions of the instruments was established to measure the homogeneity of the items for the total and dimension subscales using Cronbach's Alpha. Cronbachs Alpha coefficients were computed. Thus, the obtained Cronbach alpha coefficients results of the present pilot test and the previously reported reliability of the questionnaire are displayed in Table 1.

\section{Results}

\section{Socio-demographic characteristics of participants}

Data in Table 1 shows that the age of the respondents ranges from young-old (60 to 69) to old-old (80-89) age with comparable proportion of the two sexes. Participants' educational level extends from nil to higher education; the majority (55\%) being illiterate and the proportion gradually declining all the way up through the educational ladder. As expected, the educational level of female elderly turns out to be much worse than males across all levels.

\section{Status on psychological well-being}

Descriptive characteristics of the variables and their measurement are depicted in Table 2. As indicated earlier, the reliability of all the six sub scales is pretty good and comparable with the original indices. Keeping in view the cut off scores for different levels of psychological well-being already developed in the original sub scales, it can be said that the mean scores of participants in all the three sub-scales (autonomy, self-esteem, and depression) places them somewhere in the moderate level. That is, the elderly are moderately autonomous (Mean= $31)$, self-valuing $(\mathrm{Mean}=16)$, and depressed $(\mathrm{Mean}=16)$.

\section{Status on existential orientation}

Table 2 still presents descriptive measures on existential variables. Unlike the psychological well-being sub-scales, original measures of 


\begin{tabular}{|c|c|c|c|c|c|c|c|}
\hline \multirow{3}{*}{ Variables } & \multirow{3}{*}{ Category } & \multicolumn{4}{|c|}{ Gender } & \multirow{2}{*}{\multicolumn{2}{|c|}{ Total }} \\
\hline & & \multicolumn{2}{|c|}{ Male } & \multicolumn{2}{|c|}{ Female } & & \\
\hline & & Freq. & $\%$ & Freq. & $\%$ & Freq. & $\%$ \\
\hline \multirow{4}{*}{ Age inYears } & $60-69$ & 56 & 38.10 & 59 & 37.34 & 115 & 37.70 \\
\hline & $70-79$ & 57 & 38.77 & 61 & 38.61 & 118 & 38.70 \\
\hline & $80-89$ & 34 & 23.13 & 38 & 24.05 & 72 & 23.60 \\
\hline & Total & 147 & 100.00 & 158 & 100.00 & 305 & 100.00 \\
\hline \multirow{5}{*}{$\begin{array}{c}\text { Educational } \\
\text { Levels }\end{array}$} & Illiterate & 63 & 42.86 & 104 & 65.82 & 167 & 54.8 \\
\hline & Primary education & 33 & 22.45 & 33 & 20.88 & 66 & 21.6 \\
\hline & Secondary education & 24 & 16.32 & 12 & 7.60 & 36 & 11.8 \\
\hline & Tertiary education & 27 & 18.37 & 9 & 5.70 & 36 & 11.8 \\
\hline & Total & 147 & 100.00 & 158 & 100.00 & 305 & 100.00 \\
\hline
\end{tabular}

Table 1: Demographic characteristics of study subjects $(\mathrm{N}=305)$.

\begin{tabular}{|c|c|c|c|c|c|c|c|c|c|c|c|c|}
\hline & & & & Reliabili & indices & Cut of $s$ & res showin & status & & ige & & \\
\hline & & & & & & & & & & & & \\
\hline & Autonomy & 9 & 6 & 0.83 & 0.70 & $9-26$ & $27-35$ & $36-54$ & 9 & 54 & 31 & 8 \\
\hline Psyo & Self-esteem & 10 & $4(0-3)$ & 0.85 & 0.71 & $0-14$ & $15-25$ & $26-30$ & 0 & 30 & 16 & 6 \\
\hline & Depression & 10 & $4(0-3)$ & 0.97 & 0.84 & $0-14$ & $15-21$ & $22-30$ & 0 & 30 & 16 & 7 \\
\hline & $\begin{array}{c}\text { Religious } \\
\text { Involvement }\end{array}$ & 6 & 6 & 0.76 & 0.79 & & & & 6 & 36 & 25 & 5 \\
\hline Existential variables & Spirituality & 10 & 6 & 0.90 & 0.93 & & & & 10 & 60 & 48 & 8 \\
\hline & $\begin{array}{c}\text { Personal } \\
\text { meaning in life }\end{array}$ & 16 & 5 & 0.91 & 0.76 & & & & 16 & 80 & 63 & 8 \\
\hline
\end{tabular}

Table 2: Descriptive characteristics of variables and their measurement $(\mathrm{N}=305)$.

the existential variables didn't develop cut off scores for interpreting participants' scores. However, keeping in view theoretical or expected mean scores, it can be said that the observed means of 'religious involvement' ( $m e a n=25)$ is greater than the expected one (i.e., $21=\mathrm{a}$ midpoint of 3.5 for a scale with six rating points $\times$ six items). The same holds true for 'spirituality' (observed mean $=48$, expected mean $=35=3.5$ $\times 10$ ) and 'personal meaning in life' (observed mean $=63$, expected mean $=48=3 \times 16$ ). This would suggest, at least in crude terms, that the elderly's existential orientation is much better than their psychological wellbeing.

\section{Socio-demographic actors and psychological well-being measures}

Attempts are made in this section to determine factors explaining psychological well-being. We shall begin with the most commonly suggested factors in gerent logical research (i.e., socio-demographic variables). The three possible explanatory variables selected as a candidate for inclusion in the bivariate correlation model are sex, age, and education. Table 3 depicts that in our present sample, there is no difference in age between the two sexes; unlike what is commonly portrayed in gerentological literature that on the average females live longer than males. Note that the correlation between a dummy variable (sex) and continuous variable (age) is like an independent t-test of differences in the means of the two dummy categories (i.e., female $=1$ and male $=0$ ) on the continuous variable. The sign of the correlation matrix defines the categories represented in the dummy variable. If the correlation value is, for example, negatively significant, it means that the category of the dummy variable represented by the lesser value (i.e., males in our present case are coded with a value of 'zero') is significantly lesser in age. In the same way, significant positive correlations mean females outperform males while non-significant correlations imply no difference between the two groups. Accordingly, while there are no age differences between the two sexes, females, on the other hand, are significantly less educated than males. Note also that there is a strong negative correlation between age and educational level implying that the elderly with advanced age are likely less to be less privileged as educational access in Ethiopia was a challenge in the past but has gradually improved over time.

The correlation matrix suggests that males are significantly better in autonomy, self-esteem and depression score than females. It can also be seen in the same table that advances in age would mean decline in self-esteem and autonomy and incline in depression score. This pattern is contrary to the role of education in which better education means better autonomy and self-esteem but more depression. Lastly, we can also see that the three components of psychological well-being are strongly correlated implying that they all cluster towards measuring the same construct; psychological well-being.

Existential factors and measures of psychological well-being: The bivariate correlation indices in Table 4 suggest that all the three existential factors appear to strongly correlate with the psychological well-being measures except for the correlation between 'religious involvement' and 'autonomy'. It can also be noted in Table 4 that in as much as there are significant correlations between existential (predictor) and well-being (criterion) measures, there are at the same time significant relationships among the predictor variables (existential factors) themselves. Hence, this overlap needs to be statistically 


\begin{tabular}{|c|c|c|c|c|c|}
\hline Variables & Sex & Age & Educational & Autonomy & Self-esteem \\
\hline Sex (=1 if female, $=0$ if male) & 1 & & & & \\
\hline \multicolumn{6}{|l|}{ Age } \\
\hline Educational level & 0.011 & 1 & & & \\
\hline Autonomy & & & 1 & & \\
\hline Self-esteem & $-0.272^{* *}$ & $-0.293^{\star *}$ & & & \\
\hline \multirow[t]{3}{*}{ Depression } & $-0.290^{* *}$ & $-0.131^{*}$ & $0.336^{* *}$ & 1 & \\
\hline & $-0.119^{*}$ & $-0.437^{\star \star}$ & $0.407^{* *}$ & $0.370^{* *}$ & 1 \\
\hline & $.143^{*}$ & $.466^{* *}$ & $-.364^{* *}$ & $-.348^{\star *}$ & $-.635^{\star *}$ \\
\hline
\end{tabular}

Table 3: Pearson product moment correlation matrix of selected socio-demographic factors and components of psychological well-being ( $\mathrm{N}=305)$.

\begin{tabular}{|c|c|c|c|}
\hline Variables & Religious Involvement & Spirituality & Personal Meaning in Life \\
\hline Religious Involvement & 1 & & \\
\hline Spirituality & $0.266^{* *}$ & 1 & \\
\hline Personal Meaning in Life & $0.196^{* *}$ & $0.123^{*}$ & 1 \\
\hline \multirow[t]{3}{*}{ Autonomy Self-Esteem Depression } & -0.015 & $0.179^{* *}$ & $0.190^{* *}$ \\
\hline & $0.233^{* *}$ & $0.194^{* *}$ & $0.335^{* *}$ \\
\hline & $-0.210^{\star *}$ & $-0.229^{* *}$ & $-0.251^{\star *}$ \\
\hline
\end{tabular}

Table 4: Correlation between existential factors and psychological well-being measures $(\mathrm{N}=305)$.

partialed out so that we would be able to determine the potency of the independent contribution of each of the existential factors in explaining well-being measures. There are different variants of multiple regression that would help getting this problem fixed. Stepwise multiple regression is selected to be more meaningful for our present purpose. This analysis is summarized in Table 5.

As it can be noted in Table 5, the stepwise regression analysis has yielded that even after partialling out the overlaps among existential factors, their independent contribution still remains to be substantially significant which doesn't seem the case for the socio-demographic factors.

\section{Discussion}

The first objective of this study was to assess the status of psychological well-being of the elders. Findings indicated that the participants have scored moderate level of autonomy, and self-esteem. When it comes to autonomy, it appears that in agreement with some previous research [7] the elderly appear to somehow feel self-determined and independent, resist social pressures and act in certain ways, regulate behavior from within, evaluate self by personal standards. However, findings have also suggested that males had higer level of autonomy than females as it was also noted in many other research [8]. The main reason of male elders for having significantly higher level of autonomy than female elders may be because they have good self-esteem than females. Autonomy as a psychological functioning also seemed to wane with age as it was also indicated in previous research [35]. Autonomy has also improved with educational level [6] as this means better income, enlightened and healthy life etc.

Self-esteem, the second measure of psychological well-being, was still of a reasonable level and this seems quite useful in building psychological well-being. Some investigators have regarded selfesteem to be the number one of quality of life for older people, and of adjustment and adaptation in older age [29]. Group differences were also observed in self-esteem. For example, males scored significantly high self-esteem than females. This result is consistent with that elderly males have higher self-esteem than females. Moreover, Maru [24] supported this research finding that women have shown low self- esteem as compared with men. However, the result contradicts with research findings reported by Getaneh [22], which reported that there was no statistically significant association between self-esteem and gender. One reason for the significant difference reported in this study may be that in that culture, males are motivated to externalize their feelings whereas females are required to be silent. These conditions have brought variation in self-esteem and the variation has persisted throughout adulthood. The gender empowerment issue that Getaneh [22] considered to equalize self-esteem with mean is a very unlikely scenario in Ethiopia because the gender movement in Ethiopia is a very recent phenomenon that is still limited to school and office girls and this would hardly impact on the life of the female elderly. As expected, it was also noted that better educated elderly were with better selfesteem as this would count promote independence. Similarly, Getaneh [22] research revealed that there was statistically positive significant between self-esteem and educational status of elders. But, advances in age would negotiate this independence and thereby reduce self-esteem.

Depression was the third measure of psychological well-beings that correlated significantly but obviously negatively with the first two measures. The present findings suggested that depression is not a serious concern because participants were found to have it at a moderate level. Depression was the third measure of psychological well-beings that correlated significantly but obviously negatively with the first two measures. The present findings suggested that depression is not a serious concern because participants were found to have it at a moderate level. Reker [13] findings support this research finding that elders reported moderate and high score in depression. Dzuka, and Dalbert [4] also suggested that the majority of elders' studied didn't feel depressed, unhappy, or unfulfilled. On the contrary, Blazer [36] found that $44 \%$ of older adults were high scorer, $20 \%$ with an average and $11 \%$ of them showed a lower scorer on depression. But, it was a bite worrisome for females, older adults, and educated people.

Group differences were noted in the level of depression in the sense that it was a bite worrisome for females, older adults, and less educated people. There were consistent findings regarding depression. For instance, the older age groups [14,37-40] reported that women had higher rate of depression or poorer psychological well- being than men 


\begin{tabular}{|c|c|c|c|c|c|c|c|}
\hline Variables & Model & Variables & $\mathbf{R}$ & $\mathbf{R} 2$ & R2change & F change & Sig. $F$ \\
\hline & & Entered & & & & & \\
\hline & & & & & & & change \\
\hline \multirow[t]{3}{*}{ Autonomy } & 1 & $\begin{array}{l}\text { Personal Meaning } \\
\text { in Life Spirituality }\end{array}$ & 0.19 & 0.036 & 0.036 & 11.363 & 0.001 \\
\hline & 2 & & 0.247 & 0.061 & 0.025 & 7.93 & 0.005 \\
\hline & 1 & $\begin{array}{c}\text { Personal Meaning } \\
\text { in Life }\end{array}$ & 0.33 & 0.112 & 0.112 & 38.19 & 0.001 \\
\hline \multirow[t]{10}{*}{ Self-esteem } & & $\begin{array}{c}\text { Religious } \\
\text { involvement }\end{array}$ & & & & & \\
\hline & & Spirituality & & & & & \\
\hline & 2 & & 5 & 0.141 & 0.03 & 8 & 0.001 \\
\hline & & & & & & & \\
\hline & 3 & & & 0.155 & 0.013 & & 0.03 \\
\hline & & & 0.376 & & & 10.294 & \\
\hline & & & & & & & \\
\hline & & & 0.393 & & & 4.747 & \\
\hline & 1 & $\begin{array}{c}\text { Personal Meaning } \\
\text { in Life }\end{array}$ & 0.25 & 0.063 & 0.063 & 20.44 & 0.001 \\
\hline & & $\begin{array}{c}\text { Religious } \\
\text { involvement }\end{array}$ & & & & & \\
\hline \multirow[t]{5}{*}{ Depression } & & Spirituality & & & & & \\
\hline & 2 & & 1 & 0.103 & 0.04 & 5 & 0.001 \\
\hline & 3 & & & 0.117 & 0.014 & & 0.029 \\
\hline & & & 0.321 & & & 13.384 & \\
\hline & & & 0.342 & & & 4.793 & \\
\hline
\end{tabular}

Table 5: Stepwise regression of psychological wellbeing measures on the existential factors.

did. Johnson and Cooper [41], reported that respondents from the age category of 60-69 years had low level of depression or had good psychological well-being compared to the older age groups. However, respondents in the age category of 80 years and above had poor psychological well-being or highly depressed. Dzuka and Dalbert [4], that psychological well-being decreased significantly with increasing age in both genders, reported a similar finding. One possible explanation for the similarities may be the problems associated with age. Sherina et al. [6] has still indicated that illiterate elders were eight times more likely to be depressed compared to those with formal education.

Based on the assumption of the existential paradigm [42] that individuals strive to transcend and find meaning in adversity, and the struggles of old age through a deeper contemplation of existential needs or existential life concerns, the present study also attempted to examine the relative contribution of existential factors (i.e., religious involvement, spirituality and, personal meaning in life) in predicting psychological wellbeing. Emmons [43] emphasized that, the individual's sense of personal meaning, the determination to pursue a religious and spiritual involvement and seek wholeness of one's life within oneself become the means for affirming ones own psychological wellbeing. Thus, it makes sense that a person who perceives life as meaningful and feels as he or she is in close communion with God will maintain a much more positive outlook and will be less vulnerable to depression or old age morbidity [43].

In our present case, it was learnt that the existential orientation (religious involvement, spirituality, and personal meaning in life) of the present participants was even much better than their psychological life. This is mainly because the Ethiopian society is by and large religious oriented. It has been found in the census that about $99 \%$ of the Ethiopian society subscribes to religious denomination of one kind or another [27].

It was also found out that the independent contribution of existential variables is significant for predicting psychological well-being. To begin with personal meaning in life, it has been shown that many life events are re-experienced in old age during what some researchers call the life review. It is at this time that older adults evoke and review their lives, making meaning from the events they have experienced and integrating that meaning into their personal identities [21]. Krause [15] argued that older people derive a sense of meaning in life by reflecting on their pasts, thinking about how their lives have unfolded, and how their lives have been lived (p.289). It has even been speculated that at no other time in life besides old age is a force operating so fiercely toward self-awareness (p.321). Personal meaning in life appears to be an important contributor to health and psychological well-being [44], and correlates with:

- Both physical and psychological well-being [45], with almost every aspect of psychological wellness [7,32], and, more specifically.

- A number of such psychological variables as depression, selfesteem, hope, and positive relation with others [46].

- Self-esteem and, autonomy, positive life experiences and wellbeing, successful life changes; coping and resistance to stress, dealing with traumatic events, dealing emotionally with cancer and successful ageing and acceptance of death [47-50]. 
- Self-ratings of depression [8], and self-reported symptoms of depression and general psychological distress negatively [51].

This finding was consistent with Reker [13] a sense of personal meaning in life might be expected to play an even greater role in the maintenance of self-esteem for the elderly than other existential factors. Self-esteem has been reported to be positively associated with meaningful life, religious involvement and spirituality [11].

The findings are consistent with previous findings Fry [19] showing that the combined contribution of religious involvement, spirituality and personal meaning in life to the variance of elderly depression. Consistent with indications from earlier research findings Kaldestad [52] the findings of this study, clearly support the position of earlier researchers that religious involvement and spirituality alleviate depression, anxiety and distress of old age and provide comfort in periods of distress and uncertainty. Moreover, Chandler et al. [53]; Hawkes [54]; Kaldestad [52]; Lindgren and Coursey [55] reported that spirituality, religious involvement, and meaning in one's life have positive contribution for psychological wellbeing of elderly.

In fact, some more recent research [22] sheds new light on the relationship of religious involvement, spirituality and other existential needs and concerns to the psychological wellbeing of elders. More recently, researchers contend that religiosity and spirituality protect against anxiety, alienation and loneliness of old age, including overall morbidity arising from chronic illness [50,56].

\section{Conclusion}

This research examined psychological wellbeing and the contributions of some socio-demographic and existential factors among the elderly in Dessie Town. Therefore, the following conclusions are drawn from the results and the discussion made so far:

1. The elderly's sense of autonomy and self-esteem is good, except for the depression which was in fact moderate. Gender, educational and

2. Gender, age and educational level were significantly associated with the three measures of psychological wellbeing.

3. Existential orientations (Personal meaning in life, spirituality, and religious involvement) were even better than their status of psychological wellbeing.

4. Personal meaning in life, spirituality, and religious involvement together contributed significantly to the variance in autonomy, selfesteem and depression of the elderly. Personal meaning in life had the highest contribution to the total variance in autonomy, self-esteem and depression. The contribution of spirituality was significant to the variance in autonomy, depression and self-esteem of the elderly. Furthermore, religious involvement was found to make significant contribution to the variance in self-esteem and depression but not autonomy [57,58].

\section{Recommendations}

The focus on existential constructs in the prediction of psychological wellbeing in later life provides a clarification for the kinds of psychological resources that elders require facing the challenges of aging. For improving psychological wellbeing of the elderly, elders need to establish good religious activities and make a habit of noticing the good spiritual activities, like individual praying, forgiveness in their lives and put clear goals for their lives. Male and female elders differ significantly regarding personal meaning in life, self-esteem, depression and autonomy. Therefore, it has significant implication for caregivers, social workers, nurses, and psychologists. Besides this, the society and the government and nongovernmental bodies recognize the social values, the contribution and the impact of females on national development. Therefore, different non-governmental bodies, governmental offices and religious institutions may be working together for the improvement of the elderly females' psychological well-being

Elderly with the age range of $60-69$ and 80-89 tend to differ in their needs. Therefore, social and security affairs administrators and counselors in collaborating with religious mentors and leaders, and other bodies who work with elderly need to be aware of these differences in order to provide their support necessary for enhancing their PWB. Illiterate elders had poor psychological well-being (high status of depression, low self-esteem and low autonomy) compared to respondents with tertiary, secondary and primary educated. Therefore, social affairs and security administrators in collaborating with governmental, non- governmental and religious organizations facilitate life skill training to guide their life. Personal meaning in life is one of the most salient factors for elderly psychological well-being (promoting autonomy, self-esteem and for decreasing depression). Given the importance of personal meaning as an existential predictor for elderly, and given the importance that older adults themselves attach to religious and spiritual activities, social and security affairs office may wish to build into their existing programs diverse professions, including psychologists, social workers, religious leaders, and health workers.

One factor that affects elderly psychological well-being (autonomy) as indicated by the study was insignificant support provided to elderly is their involvement in religious activities. This may due to physical health problem. Therefore, elderly need to develop different spirituality activities to compensate their involvement in religious activities. Furthermore, the religious mentors and leaders and other religious members need to help, care, and develop cooperative, supportive relationship with the elders inside and outside the institution to raise their PWB Assuming that future studies could provide similar evidence concerning the positive influence of religion and spirituality, medical professionals and health care providers for the elderly should join hands with religious professionals in providing psychological resources and support for developing a 'will to live' through personal meaning. If religiosity indicators are low, alternate strategies that rely on spirituality may be explored to enhance psychological well-being of elderly. The results of the present study concern the influence of religion, spirituality and personal meaning have special implications for counselors, social workers working in social and security offices.

Future research might examine other possible factors such as traditional measures (income, health status, social support), stressful life events(loneliness, single, bereaved, all children left home, survival skills) and other existential factors (such as personal choice, optimism, life control, death acceptance, freedom a n d responsibility, isolation and meaninglessness, the will to meaning) and possible others that might influence psychological well-being of the elders using different data collection techniques, including the perspectives of others such as care givers, neighbors of the elders and social and security affairs workers and by having a representative sample of elders from all kebeles of Dessie Town. Finally, future research pertaining to existential predictors should pursue detail qualitative data gathering to explore in detail the precise influence of religious involvement and spiritual expression on older adults personal meaning in life and their psychological wellbeing in Dessie Town, will serve to continue to advance our knowledge in this area.

\section{References}

1. Deci EL, Ryan RM (2008) Hedonia, eudaimonia, and well-being: An introduction Journal of Happiness Studies 9: 1-11.

2. Diener E, Suh EM, Lucas RE, Smith HL (1999) Subjective well-being: Three decade of progress. Psychol Bulle 125: 276-302.

3. Ryan RM, Deci EL (2001) On happiness and human potentials: A review of research on hedonic and eudaimonic well-being. Annu Rev Psychol 52: $141-166$.

4. Dzuka J, Dalbert C (2000) Well-being as a psychological indicator of health in old age: A research agenda. Studia Psychologica 42: 61-70.

5. Diener E (2000) Subjective well-being: The science of happiness and a proposal for a national index. American Psychologist 55: 34-43.

6. Sherina MS, Nor Afiah MZ, Shamsul AS (2003) Factors associated with psychological well-being among elderly patients in a primary health care clinic in Malaysia. Asia Pacific Family Medicine 2: 148-52.

7. Ryff CD (1995) The structure of psychological well-being revisited. J Pers Soc Psychol 69: 719-727.

8. Ryff CD (1989) Happiness is everything, or is it? Explorations on the meaning of psychological well-being. J Pers Soc Psychol 57: 1069-1081.

9. Andresen EM, Malmgren JA, Carter WB, Patrick DL (1994) Screening for depression in well older adults: Evaluation of a short form of the CES-D (Center for Epidemiologic Studies Depression Scale). American Journal of Preventive 
Citation: Kibret BT, Tareke G (2017) Psychological Wellbeing of Elders as a Function of Religious Involvement, Spirituality and Personal Meaning in Life. Clin Exp Psychol 3: 153. doi: 10.4172/2471-2701.1000153

Medicine 10: 77-84.

10. Rosenberg M (1965) Society and the adolescent self-image. Princeton, Princeton University Press, New Jersey.

11. Joshi S, Kumari S, Jain M (2008) Religious belief and its relation to psychological well-being. J Indian Acad Appl Psychol 34: 345-354.

12. Cox HG (1988) Later life: The Realities of Aging (2nd edn.). Prentice-Hall, Inc, New Jersey.

13. Reker GT (1997) Personal meaning, optimism, and choice: existential predictors of depression in community and institutional elderly. The Gerontologist.

14. Blazer D, Hybels C (2005) Origins of depression in later life. Psychol Med 35: 1241-1252.

15. Krause N (2006) Religion and health in late life. Academic Press, Amsterdam.

16. Parmalee PA, Katz IR, Lawton MP (1989) Depression among institutionalized aged: Assessment and prevalence estimation. J Gerontology 44: M22-M29.

17. Levin JS (1995) Religion. The encyclopedia of aging.

18. Lukas E (1992) Meaning and goals in the chronically ill. The International Forum for Logotherapy 15: 90-98.

19. Fry PS (2001) The unique contribution of key existential factors to the prediction of psychological well-being of older adults following spousal loss. The Gerontologist 41: 69-81.

20. Miller G, Fleming W, Brown-Anderson F (1998) Spiritual well-being scale ethnic differences between Caucasians and African Americans. Journal of Psychology \& Theology 26: 358-364.

21. Fry PS (2000) Religious involvement, spirituality and personal meaning for life: Existential predictors of psychological wellbeing in community-residing and institutional care elders. Aging and Mental Health 4: 375-387.

22. Getaneh B (2010) Self-esteem and perceived adequate of social support among older persons in Debremarkos Town. Addis Ababa University, MA Thesis, Unpublished.

23. Semunigus B (2007) The self-esteem of Elderly engaged in different roles and activities: The case of residents of Yeka and Addis Keteme sub cities in Addis Ababa. Addis Ababa University, MA Thesis, Unpublished.

24. Maru Z (2009) Self-esteem depression, loneliness and coping mechanisms among retirees: The case of Addis Ababa sub cities. Addis Ababa University, MA Thesis, Unpublished.

25. Tolla T (2007) Psychosocial profile of the elderly at kaliti for the aged. Addis Ababa University, MA Thesis, Unpublished.

26. Fentie T (2010) Exploring the psychosocial profile of older people in Dangila Town. Addis Ababa University, MA thesis, Unpublished.

27. CSA (2007) National Population and Housing Census in Ethiopia, Addis Ababa Cummins, R. A. International Wellbeing Group Correspondence.

28. Bluman A (2001) Elementary statistics for a step by step Approach (4th edn.). McGraw-Hill Companies Inc, US.

29. Blascovich J, Tomaka J (1993) Measures of personality and social psychological attitudes.

30. Chatters LM, Levin JS, Taylor RJ (1992) Antecedents and dimensions of religious involvement among older Black adults. J Gerontol 47: S269-S278.

31. Reed PG (1987) Spirituality and well-being in terminally ill hospitalized adults. Res Nurs Health 10: 335-344.

32. Reker GT, Peacock EJ (1981) The Life Attitude Profile (LAP): A multidimensional instrument for assessing attitudes toward life. Can J Behav Sci 13: 264- 273.

33. Kim S (2006) Pilot testing three newly translated Korean version of questionnaires about spirituality.
34. Reker GT, Peacock EJ, Wong PT (1987) Meaning and purpose in life and wellbeing: A life-span perspective. J Gerontol 42: 44-49.

35. Ryff CD, Lee YH, Essex MJ, Schmutte PS (1994) My children and me: Midlife evaluations of grown children and self. Psychology and Aging 9: 195-205.

36. Blazer DG (1995) Depression. In: Maddox GL (ed.), The encyclopedia of aging: A comprehensive resource in gerontology and geriatrics (2nd edn.). Springer Publishing Company, New York. pp: 265-266.

37. Krause N, Goldenhar LM (1992) Acculturation and psychological distress in three groups of elderly Hispanics. J Gerontol 47: S279-S288.

38. Krause N, Herzog AR, Baker E (1992) Providing support to others and wellbeing in late life. J Gerontol 47: P300-P311.

39. Keith VM (1993) Gender, financial strain, and psychological distress among older adults. Research on Aging 15: 123-147.

40. Krause N, Liang J (1993) Stress, social support, and psychological distress among the Chinese elderly. J Gerontol 48: P282-P291.

41. Johnnson S, Cooper C 2003) The construct validity of the asset stress measure Stress and Health 19: 181-85.

42. Frankl VE (1984) Man's search for meaning, revised edition. Washington Square Press, New York.

43. Emmons RA (2003) Personal goals, life meaning, and virtue: Wellsprings of a positive life. American Psychological Association, Washington.

44. Ryff CD, Singer B (1998) Human health: New directions for the next millennium Psychological Inquiry 9: 69-85.

45. Riker AP, Brasibane HE (1997) Married and single life. Mc Graw Hill, New York.

46. Mascaro N, Rosen DH (2005) Existential meaning's role in the enhancement of hope and prevention of depressive symptoms. J Personal 74: 985-1014

47. Reker GT, Butler B (1990) Personal meaning, stress, and health in older adults. Paper presented at the Annual Meeting of the Canadian Association on Gerontology, Victoria, BC.

48. Reker GT (2005) Meaning in life of young, middle-aged, and older adults: Factorial validity, age, and gender invariance of the Personal Meaning Index (PMI). Personality and Individual Differences 38: 71-85.

49. Edwards MJ, Holden RR (2003) Coping, meaning in life, suicidal manifestations: Examining gender differences. J Clin Psychol 59: 1133- 1150.

50. Krause N (2004) Stressors arising in highly valued roles, meaning in life and the physical health status of older adults. Journal of Gerontology: Socia Sciences 59B: S287-S297.

51. Hedberg P, Gustafson Y, Alex L, Brulin C (2010) Depression in relation to purpose in life among a very old population: A five-year follow-up study. Aging \& Mental Health 14: 757-763.

52. Kaldestad E (1996) The empirical relationship between standardized measures of religiosity and personality/ mental health. Scand J Psychol 37: 205-220.

53. Chandler CK, Holden JM, Kolander CA (1992) Counseling for spiritual wellness: Theory and practice. J Couns Dev 71: 168-174.

54. Hawkes S (1994) Spiritual health: Definition and theory.

55. Lindgren KN, Coursey RC (1995) Spirituality and serious mental illness: A twopart study. Psychiatr Rehabil J 18: 93-107.

56. Koenig HG (2006) Religion, spirituality, and aging. Aging and Mental Health 10: 1-3.

57. Levin JS, Chatters LM, Taylor RJ (1995) Religious effects on health status and life satisfaction among Black Americans. J Gerontol 50B: S154- S163.

58. Romer C, Klingebiel A, Tomasik MJ (2007) Gender differences in SWB Comparing societies with respect to gender equality. Social indicator research 2: $329-347$. 